\title{
X-ray Microscopic Study on Disintegration of Granite Residual Soil
}

\author{
Chengsheng Li ${ }^{1,2}$, Lingwei Kong ${ }^{1,2 *}$, Aiguo Guo ${ }^{1,2}$, Xianwei Zhang ${ }^{1,2}$ \\ ${ }^{1}$ State Key Laboratory of Geomechanics and Geotechnical Engineering, Institute of Rock and Soil Mechanics, Chinese Academy of \\ Sciences, Wuhan, Hubei 430071, China \\ ${ }^{2}$ University of Chinese Academy of Sciences, Beijing 100049, China
}

\begin{abstract}
In order to study the evolution of cracks in the initial disintegration process of granite residual soil, this study used CT scanner to scan the sample before and after 60s disintegration. Internal cracks are statistically analyzed by $3 \mathrm{D}$ reconstruction techniques. The initial crack content of granite residual soil is $0.8 \%$, and it increases to $8.1 \%$ after $60 \mathrm{~s}$ disintegration. Internal cracks of the sample are transformed into complex connected cracks, and there are many large pores formed by erosion and presented as complex geometry shape. The geometry of cracks is analyzed from three aspects: width, length and bending ratio. It is found that cracks have strong linear characteristics after 60 s disintegration, which may be related to the initial rapid infiltration damage.
\end{abstract}

\section{Introduction}

Granite residual soil is widely distributed in southern China, especially in Guangdong, Fujian, southeastern Guangxi etc. Due to its special geological origin, it has significant anisotropy. There are a large number of primary cracks inside the soil, which may cause secondary cracks or even damage when the external environment changes, and the soil is prone to softening and disintegration during wetting.

At present, research on the disintegration mechanism of soft rock is relatively systematic, but there is little research on the disintegration of soil. However, the disintegration mechanism of soft rock is consistent with the disintegration mechanism of soil in some cases. Terzaghi, Peck [1], and Caron et al. [2] believed that the infiltration caused the increase of the internal pressure of the rock and soil body and the generation of tensile stress resulting in disintegration. Moriwaki et al. [3] analyzed and classified rock disintegration from three perspectives: rock pore pressure, differential expansion, and cement dissolution. Skempton et al. [4] studied the relationship between disintegration and strength of soft rock, and the strength of rock and soil gradually decayed with disintegration time. Gautam et al. [5] compared the disintegration of mudstone in laboratory and natural conditions.

At present, many scholars have preliminary study on the disintegration of soil, but the understanding about the disintegration mechanism is not complete, especially the granitic residual soil with special gradation and easy disintegration. $\mathrm{Wu}[6]$ conducted indoor experiments to study the disintegration characteristics of granite residual soil, and divided the disintegration process into three segments based on the intuitive trend of disintegration rate, and made some preliminary explanations. Zeng [7] conducted a disintegration test on disperse samples of granite residual soil with different water content and compaction degree, and reached some useful conclusions. From the microscopic point of view, Zhang [8] analyzed the force analysis of the soil particles in granite residual soil, and initially obtained the relationship between the average rate of stable disintegration stage and effective voids and matric suction. Zhang [9] conducted a disintegration test on basalt residual soil and analyzed the impact of climate.

Most of the current researches are based on empirical observation angles and most of the descriptions of disintegration laws are qualitative and semi-quantitative. There is a lack of quantitative analysis, and there is little analysis from the microscopic point. In the natural world, the initial disintegration rule is more practical than the complete disintegration process of granite residual soil under the bare conditions of granite residual soil, such as excavation and excavation of slopes and foundation pits. With the study of cracks by the CT test [10-14], nondestructive testing becomes possible. In this paper, according to the disintegration test of granite residual soil, CT scanning instrument is used to scan the internal cracks of the sample after initial disintegration, and the distribution and evolution of cracks are explored from the macro and micro perspectives, and the micro mechanism of disintegration is explored.

* Corresponding author: lwkong@whrsm.ac.cn 


\section{Experimental methods}

The sample selection site is located in a foundation pit near the Houhai subway station in Shenzhen, Guangdong, China (north latitude: $22^{\circ} 32^{\prime} 25^{\prime \prime}$, longitude $113^{\circ} 53^{\prime} 35^{\prime \prime}$ ). From the top to the bottom, the site is: the Quaternary Holocene fill (stone) layer $(0 \sim 5.7 \mathrm{~m})$; the marine sedimentary layer $(5.7 \sim 7.9 \mathrm{~m})$; the Quaternary Holocene alluvial deposit (7.9 ) 9.3m); residual soil layer (9.3 20.8m) and below Yanshanian granite (below $20.8 \mathrm{~m})$. The rig is combined with a thick-walled earth borrower for sampling. The basic physical indexes of the sample are shown in Table 1. It can be seen that the particle gradation of granite residual soil has the characteristics of decreasing both ends, the soil has higher plasticity index and larger permeability coefficient, and has the characteristics of high liquid limit soil and sand; quartz content with depth is gradually increasing.

We used a conventional micro X-ray CT scanning system. The highest X-ray voltage is $160 \mathrm{kV}$, and the best resolution is $10 \mu \mathrm{m}$. The sample is placed on a computercontrolled rotary table. During the test, the X-ray source did not move and the sample uniformly rotated from $0^{\circ}$ to $360^{\circ}$ on the horizontal plane, and the sample size is: $d=$ $39.1 \mathrm{~mm}, h=81.4 \mathrm{~mm}$.

First, the sample was air dried at a constant temperature until the water content was $2.5 \%$. The sample is directly placed in water for disintegration. The disintegration curve is shown in Figure 1, the test specific operation process details can be found in [9]. The sample is finally completely disintegrated, but the paper needs to study the changes in the sample during the rapid infiltration process in the initial stage. Due to the constraints of the test methods, the samples for CT testing should not be loose, and should be prominent in the initial stage. Therefore, the medical gauze is wrapped on the outside of the sample, and then protected by a plexiglass tube, and a uniformly distributed hole is drilled in the wall of the plexiglass tube, as shown in Figure 3.

Table 1. The basic physical properties of granite residue soil

\begin{tabular}{|c|c|c|c|c|c|c|c|c|c|c|c|c|c|c|}
\hline \multirow{2}{*}{$\begin{array}{l}\text { Density } \\
\rho\left(\mathrm{g} / \mathrm{cm}^{3}\right)\end{array}$} & \multirow{2}{*}{$\begin{array}{l}\text { Specific } \\
\text { gravity } G_{\mathrm{s}}\end{array}$} & \multirow{2}{*}{$\begin{array}{l}\text { Void } \\
\text { ratioe } e_{0}\end{array}$} & \multirow{2}{*}{$\begin{array}{c}\text { Water } \\
\text { Content } \\
(\%) \\
\end{array}$} & \multirow{2}{*}{\begin{tabular}{|c|} 
Liquid \\
limit \\
$(\%)$ \\
\end{tabular}} & \multirow{2}{*}{$\begin{array}{c}\text { Plastic } \\
\text { limit } \\
(\%)\end{array}$} & \multirow{2}{*}{$\begin{array}{c}\text { Plasticity } \\
\text { index }\end{array}$} & \multirow{2}{*}{$\begin{array}{c}\text { Permeability } \\
\text { coefficient } \\
(\mathrm{m} / \mathrm{s})\end{array}$} & \multicolumn{4}{|c|}{ Grain size $(\mathrm{mm} / \%)$} & \multicolumn{3}{|c|}{$\begin{array}{c}\text { Mineral } \\
\text { composition/\% }\end{array}$} \\
\hline & & & & & & & & $>2$ & & & & & & \\
\hline & & .74 & 267 & 58.89 & 27.27 & & $1.79 \times 10^{-6}$ & 32. & & & 20 & 1.39 & 0 & 2.5 \\
\hline
\end{tabular}

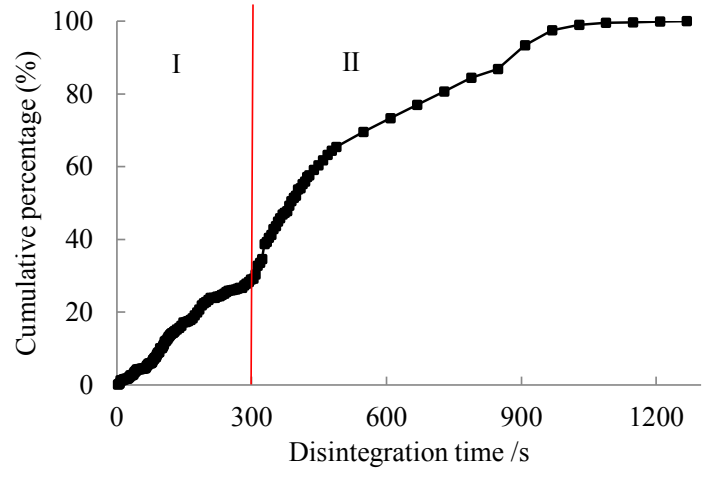

Fig. 1. The curve of disintegration test

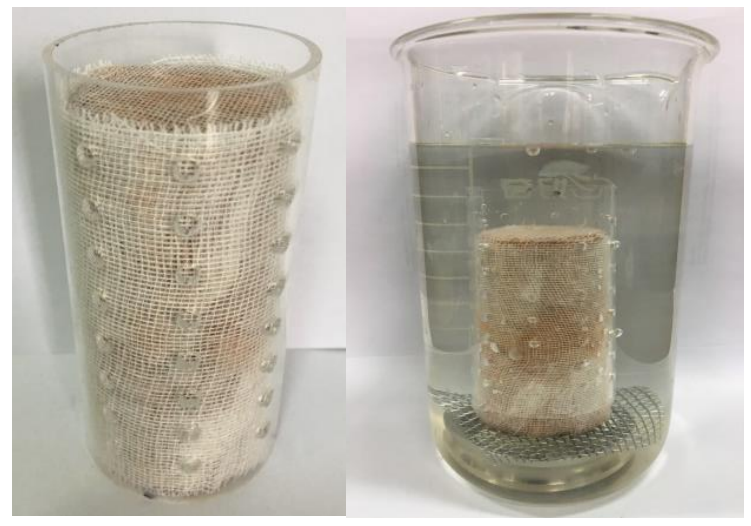

Fig. 2. Disintegration test

\section{Results and discussions}

\subsection{Reconstruction and analysis}

According to the structure and composition of granite residual soil, the original CT image was divided into four parts: crack, soil matrix, quartz and cement. The results of the segmentation are shown in Figure 3, and Table 2. Quartz is the most stable mineral in granite residual soil. It remains unchanged after disintegration for $60 \mathrm{~s}$. Therefore, the accuracy of the algorithm can be verified by the difference of quartz content. According to the particle fraction test, the part with a particle size of $>$ $0.075 \mathrm{~mm}$ is almost quartz, and the accuracy of the CT scanner is also within this range, so it can be verified based on the quartz content in this range.

As shown in Figure 3, the cracks of the granite residual soil are distributed in an irregular pattern, and among the cracks the connectivity is poor (Figure $3 \mathrm{c}$ before the test, one color represents a connected crack), and the crack distribution is anisotropic. There is an aggregation phenomenon in the local area.

After the disintegration test, large holes appeared in the local sidewalls of the sample. The maximum crack width can reach $1.91 \mathrm{~mm}$, and the maximum crack length can reach $8 \mathrm{~mm}$. The spatial distribution of cracks is crisscross, and a large number of small cracks are connected to form a larger interconnecting crack. As shown in Figure 3f, the brown part represents a single largest connected crack, which almost occupies the entire soil volume. 

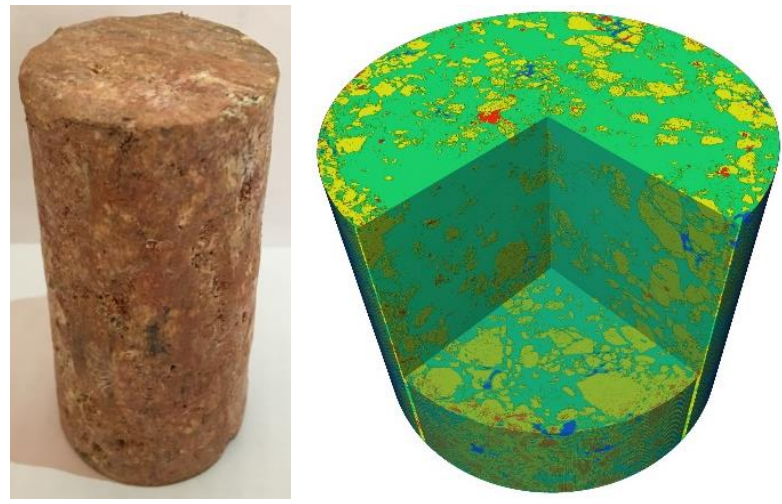

(a) Initial sample
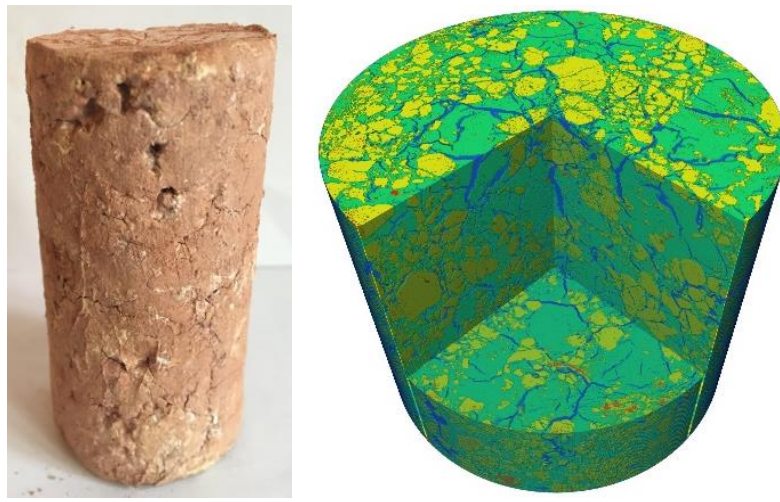

(d) Disintegration of $60 \mathrm{~s}$

(e) CT result of Disintegration

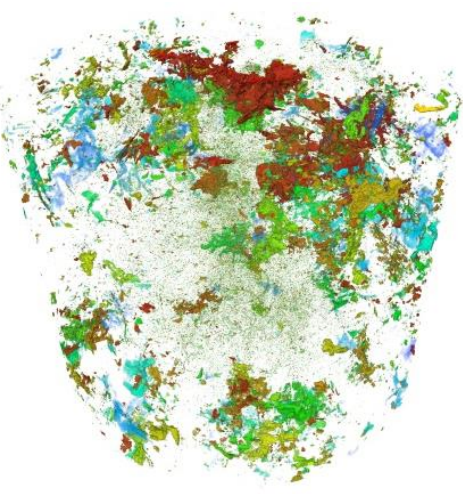

(c) Cracks of initial sample

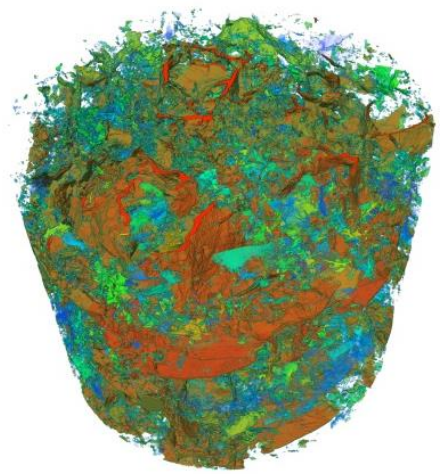

(f) Cracks of disintegration

Fig. 3. CT results of sample (b and c: blue is crack, greeen is soil, yellow is quartz; c and f: different colors represent different pore connected groups )

Table 2. Each component content

\begin{tabular}{|c|c|c|c|c|}
\hline & Crack & Soil matrix & Quartz & Cement \\
\hline Initial (\%) & 0.8 & 65.8 & 32.3 & 1.1 \\
\hline After test (\%) & 8.1 & 59.3 & 31.9 & 0.7 \\
\hline
\end{tabular}

Granite residual soil contains a large number of quartz particles and the volume is larger. Quartz particles are irregular geometric shapes, their distribution is aeolotropic, there is agglomeration phenomenon, and maintain part of the original rock structure characteristics.

As shown in Figure 4, typical representative slice diagrams are selected at different layers of the disintegrated sample. It can be seen that dendritic and irregular holes are distributed inside the sample. Among them, most of the cracks are dendritic and polylines, and there are a few smooth curves. The cracks are "traveling" around the quartz; where the quartz is densely distributed, the large cracks are generally less and only some of the cracks are large.

The large "round-hole" and "irregular geometry" cracks communicate with the small cracks. Most of the cracks are crisscrossed. Many cracks are connected to the outer wall of the sample, and the pore size of the crack gradually decreases from the outside to the inside. The formation of fissures may be related to rapid infiltration. The pore pressure caused by rapid infiltration forms a tensile stress inside the soil. When the tensile stress exceeds the strength of the soil, the soil is destroyed. Almost at the same time, the rapidly infiltrated water flows off the broken soil particles, eventually leaving large pores.

\subsection{Crack geometry}

The cracks have three important geometric properties: (1) width, (2) length, and (3) bending ratio. Since the skeletons can maintain the topological properties of cracks [15], they can also reflect the length and curvature of the cracks, so it is necessary to analyze the skeletons of the cracks. Since the crack is a complex curved surface with thickness, it is difficult to accurately define the length and curvature of the extracted three-dimensional skeleton. Therefore, the two-dimensional slice analysis of the skeleton of the crack is preliminary.

In this paper, an iterative algorithm used to extract the crack skeleton [16], but the extracted skeletons have too many "burrs". It is difficult to analyze the skeletons' geometry, and those need to be preprocessed. The skeleton curve is trimmed according to the ratio of the length of the burr to the total length of the skeleton. In this paper, the trim ratio is chosen to be 0.05 , and the iteration is performed twice. And delete the skeleton which length less than $0.075 \mathrm{~mm}$ ( 3 pixels). 

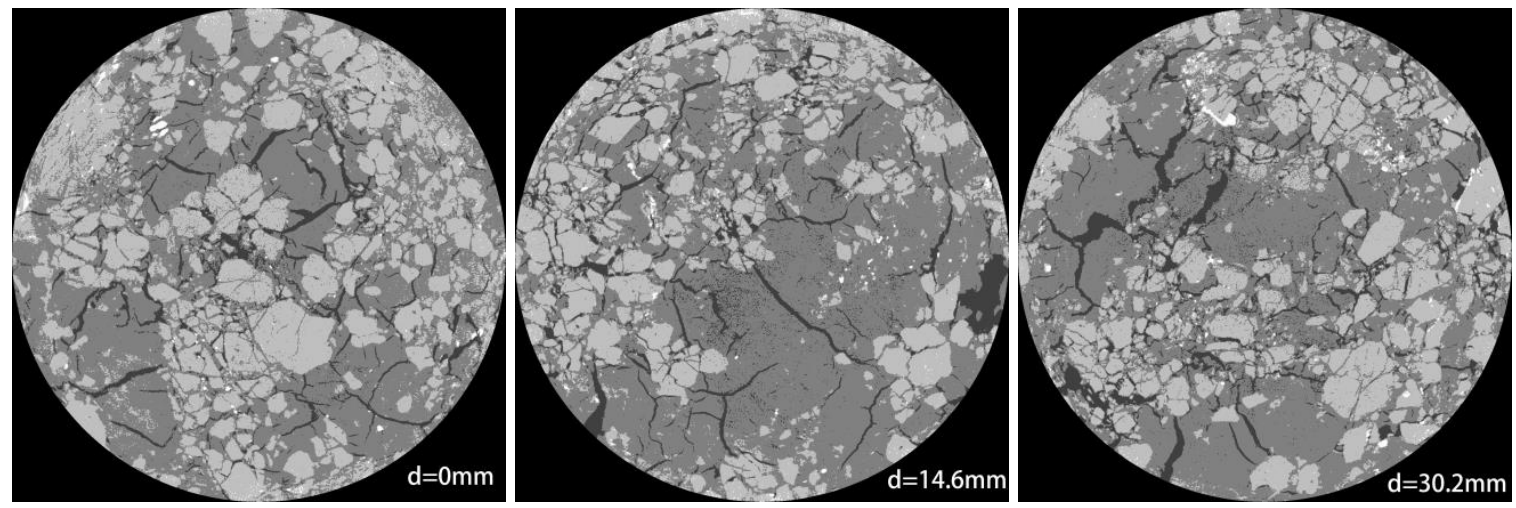

Fig. 4. CT slices showing the internal cracks of the sample ( $d$ is the distance to the first slice; different colors represent different parts, ater is background, charcoal grey is crack, grey is soil and light-grey is quartz)
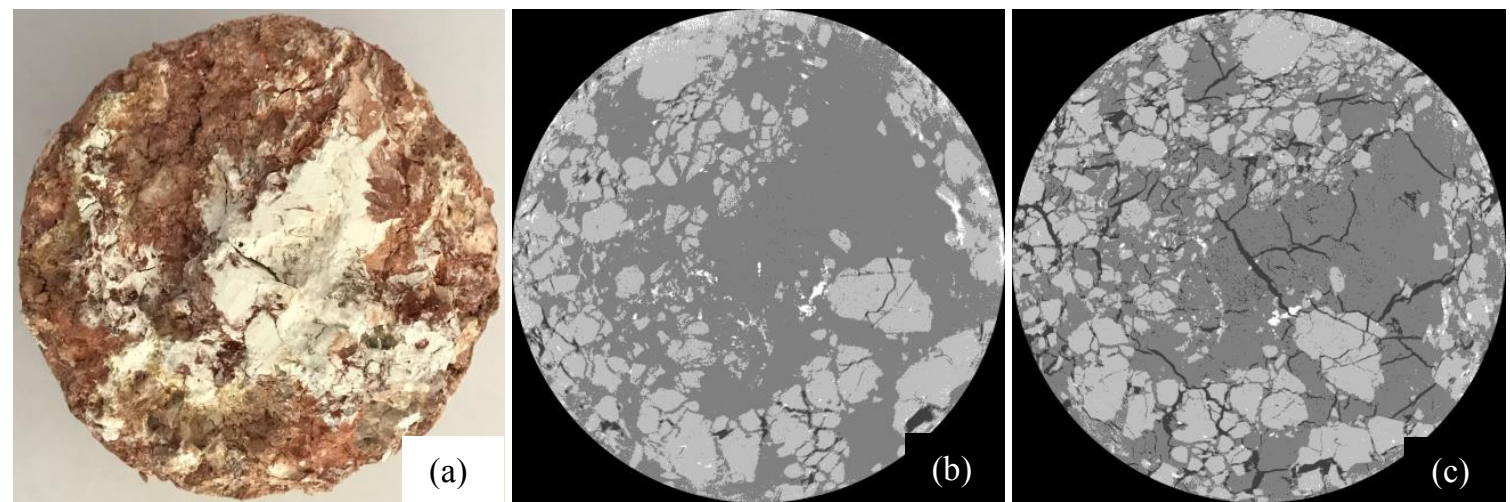

Fig. 5. Contrast images before and after the test, a) sample photo, b) Initial sample, c) Disintegration of $60 \mathrm{~s}$ (there are some colors in the sample photo, different colors represent different mineral composition, and the charcoal grey is crack)

According to the mathematical morphology of CT images, the total length of the skeleton curve can be directly obtained by counting the number of pixels in the image. The bending ratio of curvature of a continuous curve under ideal conditions can be described by curvature, but the curvature of a curve is infinite and cannot be directly described by a single index, therefore, it is approximated by its overall shape. Define the skeletal curve bending index as: the ratio of the total length of the skeleton curve to the maximum distance of the endpoints:

$$
c=\frac{l_{\text {total }}}{d_{\max }}
$$

The distribution of the length of the skeleton curve and the curvature index are shown in Figure 6. It shown that both the length of the skeleton curve and the bending ratio increasing after disintegration, and the proportion of the increase in the length of the skeleton curve is greater. The results show that the cracks geometry becomes more complex. As shown in Figure 6, based on the initial cracks, the cracks gradually evolved in terms of length, bending, and width. It is obvious that the expansion speed of cracks is greater than the increase of the bending rate in the length, which means that in the rapid infiltration process of water, the development speed of crack destruction may be high, and the infiltration water flow erosion is similar to the tubular erosion, and their linear characteristic is significant.

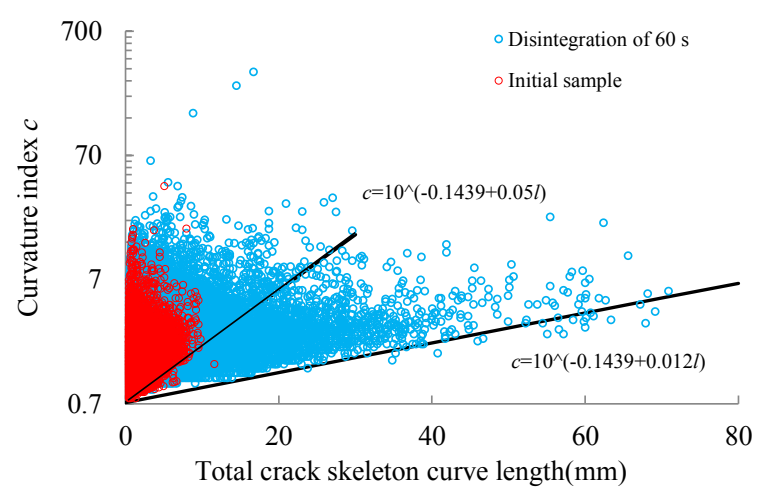

Fig. 6. The distribution of skeleton length and curvature index

As shown in Figure 7, the initial cracks are mainly concentrated in the range of $0 \sim 0.2 \mathrm{~mm}$, accounting for about $91.07 \%$ of the whole, and macropores content are rarely. While the pore size distribution curve of the sample after disintegration is mainly concentrated in the range of $0 \sim 0.6 \mathrm{~mm}$, accounting for about $89.47 \%$. It can be seen that the cracks in the sample become more slender after disintegration, and the pore size of the cracks also increases, so the proportion of content increases in the range of $0 \sim 0.6 \mathrm{~mm}$; there are a small number of large pores, and there are some cracks more than $1.0 \mathrm{~mm}$. 


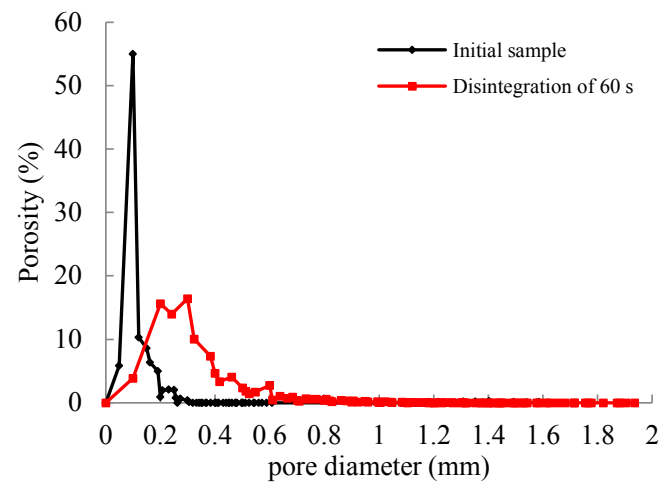

Fig. 7. Radial porosity for samples

\section{Conclusions}

(1) The cause of the easy disintegration of granite residual soil is preliminarily determined by its primary fracture and gradation characteristics. The high content of quartz coarse particles and the development of primary fractures provide good conditions for rapid infiltration.

(2) A quantitative analysis of the macro-micro cracks formed by disintegration, using the most stable quartz as the spatial location matching benchmark, was performed. After the sample disintegrated for $60 \mathrm{~s}$, the crack content increased from $0.8 \%$ to $8.1 \%$, the initial cracks evolved directly into the larger connected cracks.

(3) Quantitative description of the fracture geometry before and after the test. The skeleton curve of the fracture is extracted, and the bending index, length and distribution of the fracture pore diameter of the fracture skeleton curve are counted. It is found that the length of the primary fracture skeleton is generally less than $10 \mathrm{~mm}$, but the length of the fracture skeleton curve can reach 70 $\mathrm{mm}$ after disintegration for $60 \mathrm{~s}$. According to the bending index and the pore size distribution, the skeleton curve is more linearly distributed, indicating that the fracture formed by the disintegration test has a strong linear characteristic.

The authors would like to acknowledge financial support from the National Natural Science Foundation of China (Grant No. 11672320) and the Science and Technology Service Network Initiative of the Chinese Academy of Sciences (Grant No. KFJEW-STS-122).

\section{References}

1. K. Terzaghi, R.B. Peck, Soil mechanics in engineering practice; second edition, (1967)

2. J.Caron, C.R. Espindola, D.A. Angers, Soil Science Society of America J., 60, 3, 901-908, (1996)

3. Y. Moriwaki, Causes of slaking in argillaceous materials, (1975)

4. A.W. Skempton, Slope Stability of Cuttings in Brown London Clay. Thomas Telford, (1984)

5. T.P. Gautam, A. Shakoor, Rock Mech. \& Rock Eng., 49, 1, 19-31, (2016)
6. Wu Nengsen, J. of Hebei Institute of Architectural Science and Technology, 23, 3, 58-62, (2006)

7. Z. Peng. A Study on Compaction Characteristics and Disintegration Behavior of Granite Residualsoil. South China University of Technology, (2012)

8. S. Zhang, H. Tang, Rock and Soil Mech., 34 ,6, 001668-1674, (2013)

9. X. Zhang, L. Kong, C. Chen, S. Yin, Sc. Sinica, 46, 11, 1175-1184, (2016)

10. Y. Chen, N. Li, X. Han, Y. Pu, Q. Liao, Chinese J. of Rock Mech. and Eng., 24, 15, 2665-2670, (2005)

11. T. Li, H Lu, Chinese J. of Rock Mech. and Eng., 29, 2, 289-296, (2010)

12. P. Gehre, C.G. Aneziris, Ceramics International, 37, 6, 1731-1737, (2011)

13. J. Dewanckele, Science of the Total Environment, 416, 2, 436-448, (2012)

14. H.C. Sang, Minerals Engineering, 57, 2, 79-85, (2014)

15. H. Li, C. Bingzhi, G. Xiaoshan, J. of ComputerAided Design \& Computer Graphics, 21, 9, 1227 1231, (2009)

16. L.Lam, S.W. Lee, C.Y. Suen, IEEE Transactions on Pattern Analysis \& Machine Intelligence, 14, 9, 869885, (1992) 